\title{
When discards survive: Accounting for survival of discards in fisheries assessments
}

\author{
Benoit Mesnil
}

IFREMER, place du Séminaire, BP 7, 17137 L'Houmeau, France.

Received January 26, 1996; accepted April 3, 1996.

Mesnil B. Aquat. Living Resour., 1996, 9, 209-215.

\begin{abstract}
When discards data are included in fish stock assessments, it is generally assumed that all discarded animals die. However, there are fisheries in which a significant fraction of discards are able to survive. This case can be treated with a simple extension of the usual analytical model of exploited populations, enabling Virtual Population Analysis (VPA) to be used for parameter estimation. The paper examines the effects on estimates obtained by VPA when discards are allowed to survive, and validates a procedure for deriving partial fishing mortalities in multiple-fleet fisheries where discarding and survival rates are fleet specific.
\end{abstract}

Keywords: Stock assessment, discards, Virtual Population Analysis, multiple-fleet fisheries.

Prise en compte de la survie des rejets dans les évaluations de stocks.

Résumé

Lorsque les évaluations de stocks halieutiques prennent en compte l'existence de rejets, on considère généralement que tous les animaux rejetés meurent. Il existe toutefois des pêcheries dans lesquelles une proportion significative des rejets peut survivre. Une modification simple du modèle analytique usuel permet de traiter ces cas particuliers, en préservant la possibilité d'estimer les paramètres à l'aide d'analyses de cohortes. Les effets de la prise en compte d'une survie des rejets sur les estimations d'effectifs et de mortalités par pêche sont examinés dans cet article. On précise aussi la procédure à suivre pour estimer les mortalités par pêche partielles pour les pêcheries dans lesquelles les taux de rejets et de survie diffèrent selon les flottilles.

Mots-clés : Évaluations de stocks, rejets, analyses de cohortes, pêcheries multi-métiers.

\section{INTRODUCTION}

Discarding is a pervasive feature of many fisheries throughout the world. A global review (Alverson et al., 1994) indicates that an average of about 27 million tonnes of marine species are discarded each year in commercial fisheries worldwide, amounting to nearly one third of the annual landings of 83 million tonnes reported to FAO. Disposal of fish after capture may be due to a mix of operational (hold or processing capacity), economic (lack or glut of market, high-grading) or legal (minimum landing size, quotas or trip limits) reasons (CEC, 1992; Gillis et al., 1995). The root cause, however, is the lack of selectivity of fishing gears or operations, both within and among species, notably in trawl fisheries (Murawski, 1993). Apart from the ethical issues ("wastage of scarce resources"), discarding poses a number of problems for assessment and management of fisheries. When based on landings only rather 
than on total catches, estimates of fishing mortality, stock abundance or productivity can be seriously biased (Anon., 1986), with the additional difficulty that the bias is variable whenever discarding rates are size specific or depend on year class strength. Including discards in assessments is critical for proper evaluations of technical interactions in mixed fisheries, of multispecies interactions, and of ecosystem effects of fishing (Anon., 1992). Since fishermen are generally reluctant to report the amounts discarded, there is a large extra cost involved in obtaining representative discards data besides the landings estimates, by recourse to on-board observers or research vessels surveys.

It is generally considered that none or very few of the discarded animals survive when returned to the sea. This is probably a valid assumption for most finfish species taken by trawl-like gears, although significant rates of survival of discarded fish (notably flatfish) may be observed in some fisheries (Neilson et al., 1989; Williams et al., 1989; Hill and Wassenberg, 1990; van Beek et al., 1990; Berghahn et al., 1992). Several crustacean species (crabs, lobsters) are relatively robust and are likely to survive in large proportions when discarded, notably those caught in pot fisheries (Stevens, 1990). Even for the more fragile Norway lobster (Nephrops norvegicus), experiments on discards in the Bay of Biscay trawl fishery showed average survival rates of 30\% (Gueguen and Charuau, 1975), and this estimate has been used in ICES assessments (Anon., 1980; 1990). An extreme case is that of the Florida stone crab fishery where only the claws above legal size are retained and the body must be returned to the sea; yet, up to $50 \%$ of the amputated animals are able to survive and regenerate their claws (Restrepo, 1992). Several bivalve molluscs such as scallops are also likely to survive discarding unless severely damaged. The factors usually recognized to affect the survival of discards are the species and size, depth of capture, gear type, tow duration, volume and composition of the catch, method of sorting and handling, season, air temperature (Ricker, 1976; van Beek et al., 1989; Wassenberg and Hill, 1989).

There are thus cases for which appropriate assessment models must be used, that account for some survival of the discards. This paper elaborates on an extension of the conventional age-structured model previously proposed by R. Jones (Anon., 1980). The effects of survival of discards on the estimates of stock number and fishing mortality at age (or length) obtained by Virtual Population Analysis (VPA, see e.g. Megrey, 1989 for a review of this method) are examined. A particular attention is paid to the derivation of partial fishing mortalities for multiplefleet fisheries in which discarding and survival rates differ among fleets. Implications for assessments are also discussed.

\section{The model}

The following notation will be used:

$i=$ age or length class

$C_{i}=$ catch in number

$L_{i}=$ landings in number

$P_{i}=L_{i} / C_{i}=$ proportion landed, $0 \leq P_{i} \leq 1$

$D_{i}=$ discards in number $=C_{i}\left(1-P_{i}\right)$

$S_{i}=$ survival rate of discards, $0 \leq S_{i} \leq 1$

$K_{i}=$ removal/catch ratio, $0 \leq K_{i} \leq 1$

$N_{i}=$ population size in number

$M_{i}=$ instantaneous rate of natural mortality

$F_{i}=$ instantaneous rate of "nominal" (catch related) fishing mortality

\section{Single fleet fishery}

Suppose that $C_{i}$ animals of age-group or lengthclass $i$ are caught, of which a proportion $P_{i}$ are landed. Of the $D_{i}=C_{i}\left(1-P_{i}\right)$ animals discarded, a proportion $S_{i}$ are assumed to survive. The net removal $R_{i}$ from the stock is thus given by:

$$
\begin{aligned}
R_{i} & =L_{i}+D_{i}-S_{i} D_{i} \\
& =C_{i}\left[1-S_{i}\left(1-P_{i}\right)\right] \\
& =C_{i} K_{i}
\end{aligned}
$$

Removal is equal to catch $\left(K_{i}=1\right)$ when all the catch is landed $\left(P_{2}=1\right)$ or when all discards die $\left(S_{i}=0\right)$, as assumed in most assessments.

To account for the survival of discards, the conventional model for the exploited population can be expressed as (after dropping the subscript $i$ that applies to all parameters):

$$
\begin{aligned}
\frac{d N}{d t} & =-[M+F-S(1-P) F] N \\
& =-[M+F K] N=-Z N
\end{aligned}
$$

The total mortality rate $Z$ now includes a correction for survival of part of the catch. The correction factor $K$ applied to the "nominal" fishing mortality $F$ is the same as the ratio between removal and catch. Over a time step $\Delta t$, the population of age $i$ individuals subject to exploitation decreases exponentially as:

$$
N_{i+\Delta t}=N_{i} e^{-\left[M_{i}+F_{i} K_{i}\right] \Delta t}=N_{i} e^{-Z_{i} \Delta t}
$$


The corresponding catch equation is:

$$
C_{i}=F_{i} \bar{N}_{i} \Delta t=\frac{F_{i} N_{i}\left(1-e^{-Z_{\imath} \Delta t}\right)}{Z_{i}}
$$

or, in the form used for backwards calculations in VPA:

$$
C_{i}=\frac{F_{i} N_{i+\Delta t}\left(e^{Z_{i} \Delta t}-1\right)}{Z_{i}}
$$

Note that two different notions of fishing mortality are used in $[4]$ or $\left[4^{\prime}\right]$. The term $F$ in the numerator in the right hand side is the "nominal" fishing mortality related to catch, whereas the total mortality $Z$ in the exponential and in the denominator is the combination of natural mortality $M$ and of a "corrected" fishing mortality $(K \times F)$. The two notions are reconciled when removals are considered:

$$
R_{i}=K_{i} C_{i}=\frac{K_{i} F_{i} N_{i}\left(1-e^{-Z_{\imath} \Delta t}\right)}{Z_{i}}
$$

Thus, if removals rather than catches are used as input to VPA, the usual algorithms can be used to solve this equation and provide corrected fishing mortality estimates (i.e., $K_{i} \times F_{i}$ ). However, for simulations that imply changes in the discarding ratios (e.g. changes of minimum landing size), it is preferable to handle the correction factors and the nominal $F^{\prime}$ s explicitly, which implies that the $F^{\prime}$ s given by VPA based on removals be back-transformed to nominal $F^{\prime}$ s.

\section{Multiple fleet fishery}

Complications occur when the fishery is operated by a variety of fleets or "métiers" in which discarding ratios and survival rates of discards differ (e.g. trawl vs. hand lines). Not only do we need a special form of the simulation model, but also we need to amend the VPA procedure to estimate the fleet-specific fishing mortalities. In this instance, the total mortality rate on group $i$ can be expressed as:

$$
\begin{aligned}
Z_{i} & =M_{i}+\sum_{f}\left[F_{i, f}\left(1-S_{i, f}\left(1-P_{i, f}\right)\right)\right] \\
& =M_{i}+\sum_{f}\left[F_{i, f} K_{i, f}\right]
\end{aligned}
$$

where $f$ is the fleets' subscript.

The catch and removal by each fleet are given by:

$$
C_{i, f}=F_{i, f} \bar{N}_{i} \Delta t=\frac{F_{i, f} N_{i}\left(1-e^{-Z_{i} \Delta t}\right)}{Z_{i}}
$$

and

$$
R_{i, f}=K_{i, f} C_{i, f}=\frac{K_{i, f} F_{i, f} N_{i}\left(1-c^{-Z_{i} \Delta t}\right)}{Z_{i}}
$$

respectively, the sums of which across fleets being noted $C_{i, *}=\sum_{f} C_{i, f}$ and $R_{i, *}=\sum_{f} R_{i, f}$.

When there is no survival of discards (all $K^{\prime} S$ are unity), VPA based on total catches $C_{i, *}$ provides the total fishing mortality $F_{i,{ }^{*}}$, which can be split in proportion to the catch number by fleet to estimate the partial fishing mortalities by fleet under the assumption that all fleets encounter the same mean number of group $i$ fish during the time interval $\Delta t$, i.e.:

$$
F_{i, f}=F_{i, *} \frac{C_{i, f}}{C_{i, *}}
$$

Things are not as straightforward when discards survive since the catch equation is non-linear with respect to the total mortality rate $Z$, which combines corrected $F^{\prime}$ s involving variable correction factors. So, there is no direct relationship between partial $F^{\prime}$ s, partial catches, and total $F^{\prime} \mathrm{s}$ obtained by solving the catch equation using total catch. The only case for which a simplification can be presumed is when the $K^{\prime}$ s are equal across fleets, but this situation would be exceptional in practice. A multivariate minimization method seems to be required to solve the system of equations [7] given the catch of each fleet and the survivors at the next age or size. This was the approach used in the extension of length-based VPA and simulation software known in some ICES Working Groups as MSFL (Anon., 1990; Mesnil and Shepherd, 1990).

However, a further exploration of the problem led to a much simpler solution. If net removals (eq. [8]) rather than catches are considered, then all fishing mortalities are consistently corrected $F^{\prime}$ s. An ordinary VPA algorithm can then be used to solve the equation for total removals of group $i$ :

$$
R_{i, *}=\frac{\hat{F}_{i, *} N_{i+1}\left(e^{Z_{i} \Delta t}-1\right)}{Z_{i}}
$$

whereby the estimated total fishing mortality $\hat{F}_{i, *}$ can be shown to be the sum of the corrected $F^{\prime}$ s, i.e.:

$$
\hat{F}_{i, *}=\sum_{f} F_{i, f} K_{i, f}
$$

As will become clearer from the second example, a further advantage of this approach is that it allows the derivation of the partial corrected fishing mortalities proportional to the removals by each fleet, as :

$$
\left(F_{i, f} K_{i, f}\right)=\hat{F}_{i, *} \frac{R_{i, f}}{R_{i,{ }^{*}}}
$$


Table 1. - Single fleet fishery. Input data corresponding to a single cohort.

\begin{tabular}{rrllll}
\hline Age & $\begin{array}{l}\text { Number } \\
\text { caught } C\end{array}$ & $\begin{array}{l}\text { Proportion } \\
\text { landed } P\end{array}$ & $\begin{array}{l}\text { Rate of } \\
\text { survival } S\end{array}$ & $\begin{array}{l}\text { Correction } \\
\text { factor } K\end{array}$ & $\begin{array}{l}\text { Numer } \\
\text { removed } R\end{array}$ \\
\hline 2 & 421.0 & 0.06 & 0.30 & 0.718 & 302.3 \\
3 & 2136.0 & 0.09 & 0.30 & 0.727 & 1552.9 \\
4 & 4798.0 & 0.33 & 0.30 & 0.799 & 3833.6 \\
5 & 3522.0 & 0.72 & 0.30 & 0.916 & 3226.2 \\
6 & 2578.0 & 0.92 & 0.30 & 0.976 & 2516.1 \\
7 & 1265.0 & 0.98 & 0.30 & 0.994 & 1257.4 \\
8 & 749.0 & 1.00 & 0.30 & 1.000 & 749.0 \\
9 & 308.0 & 1.00 & 0.30 & 1.000 & 308.0 \\
10 & 178.0 & 1.00 & 0.30 & 1.000 & 178.0 \\
\hline
\end{tabular}

This provides the same simple relationships between removals (corrected catches) and corrected $F^{\prime} s$ as we had between catches and $F^{\prime} s$ in the absence of survival, even though the correcting factors differ by fleet.

As in the single-fleet case, if we are interested in forward predictions that suppose changes in the rates of discarding, we must revert to nominal $F^{\prime \prime}$ s. The latter can be obtained simply by dividing the corrected partial $F^{\prime} s$ by the relevant correcting factor $K_{i, f}$ for each fleet or, alternatively, from:

$$
F_{i, f}^{\prime}=\hat{F}_{i, *} \frac{C_{i, f}}{R_{i, *}}
$$

\section{Examples}

\section{Single fleet fishery}

The first example illustrates how estimates obtained by VPA are changed when the survival of discards is taken into account. For simplicity, a single cohort is considered with annual data by age. The input data are given in Table 1, which shows the catch, proportion landed and survival rate (assumed a constant $30 \%$ ) at each age. The correction factors $K$ and net removals at each age were computed according to equation [1]. The fishing mortalities and populations numbers at age estimated by VPA based on catches are shown in Table 2, and can be compared with the results obtained when VPA is based on removals.

Obviously, there is no difference in estimates for ages 8-10, which are all landed, but results start to diverge as VPA proceeds backwards from age 7 to age 2. Accounting for the survival of discards translates into a reduction in the estimated fishing mortalities. One can check that the corrected $F^{\prime \prime} \mathrm{s}$ in the fourth column are the nominal $F^{\prime}$ s from the second column multiplied by the age-specific $K^{\prime}$ s. Since all $K^{\prime}$ s are less than or equal to unity, the corrected $F^{\prime} \mathrm{S}$ are necessarily smaller or unchanged compared to nominal $F^{\prime}$ s. This result is rather obvious: if some fish are taken and then returned alive to the sea, this is equivalent to them not being taken at all, and the actual
Table 2. - Comparison of VPA estimates of fishing mortalitics and stock sizes at age depending on whether survival of discards is accounted for (removals, right columns) or not (catches, left columns). $M$ is assumed to be 0.2 per year at all ages in both cases.

\begin{tabular}{clllcl}
\hline & \multicolumn{2}{c}{ VPA based on Catches $C$} & & \multicolumn{2}{c}{ VPA based on Removals $R$} \\
\cline { 2 - 3 } \cline { 5 - 5 } Age & Nominal $F$ & Stock size & & Corrected $F$ & Stock size \\
\hline 2 & 0.012 & 37759.0 & 0.010 & 3450.5 .3 \\
3 & 0.080 & 30534.2 & & 0.063 & 27977.5 \\
4 & 0.259 & $23(072.4$ & & 0.218 & 21504.8 \\
5 & 0.308 & 14574.5 & & 0.288 & 14156.1 \\
6 & 0.389 & 8767.3 & & 0.382 & 8689.7 \\
7 & 0.336 & 4864.3 & & 0.334 & 4856.0 \\
8 & 0.341 & 2846.2 & 0.341 & 2846.2 \\
9 & 0.228 & 1657.5 & 0.228 & 1657.5 \\
10 & 0.200 & 1079.8 & 0.200 & 1079.8 \\
\hline
\end{tabular}

fishing mortality must be smaller than if they were effectively killed. In VPA generally, smaller fishing mortalities are associated with larger stock size. This is not the case here: the estimated stock numbers at age (fifth column) are also reduced. This is not simply due to the way VPA works (lower $F^{\prime}$ s for the same survivors giving smaller numbers at the start of the year). The reason is that surviving discards may contribute several times to the catch and, therefore, a given catch can be realized from a smaller stock.

\section{Multiple fleet fishery}

This example serves to illustrate the derivation of partial fishing mortalities by fleet when discarding and survival rates are fleet specific. For that purpose, it is sufficient to just consider a single age group. Catch data were generated artificially with the parameters given in Table 3 . The total mortality accounting for survival (eq. [6]) is $Z=1.378$, giving 2521 survivors out of the initial population of 10000 individuals. If we suppose that the age considered is the oldest one at which discarding takes place, and that fish of subsequent ages are all landed, then the number of survivors of this age provided by VPA as it proceeds backwards is not affected by errors due to discarding and survival being accounted for or not (like age 7 in the previous example).

If we use an ordinary VPA algorithm to solve equation [10] with the number of survivors $N_{i+1}$ given above and total removals $R_{i}$ * of 6393 , we get the right estimates of 10000 for the initial number and of 1.178 for the sum of fishing mortalities $\hat{F}_{i, *}$. Considering fleet 2 for example, the estimated partial fishing mortality based on partial removal (eq. [12]) is : $(1.178 \times 2767.6 / 6393.0)=0.510$, which is the right corrected $F$ for this fleet. The uncorrected $F$ obtained with equation [13] is: $(1.178 \times 3256 / 6393)=0.60$ and is also exact.

If, instead, we solve the normal catch equation by ordinary VPA, given a total catch of 7055 and the same number of survivors, the initial population size 
Table 3. - Multiple-fleet fishery. Artificial data for a single age group. Stock number at start $=10000 ; M=0.2$.

\begin{tabular}{|c|c|c|c|c|c|c|c|}
\hline Fleet & $\begin{array}{l}\text { Proportion } \\
\text { landed } P\end{array}$ & $\begin{array}{l}\text { Rate of } \\
\text { survival } S\end{array}$ & $\begin{array}{l}\text { Corection } \\
\text { factor } K\end{array}$ & $\begin{array}{l}\text { Nominal } \\
F\end{array}$ & $\begin{array}{l}\text { Corrected } \\
F\end{array}$ & $\begin{array}{l}\text { Number } \\
\text { caught } C\end{array}$ & $\begin{array}{l}\text { Number } \\
\text { removed } R\end{array}$ \\
\hline 1 & 0.80 & 0.00 & 1.00 & 0.50 & 0.500 & 2714.0 & 2714.0 \\
\hline 3 & 0.20 & 0.20 & 0.84 & 0.20 & 0.168 & 1085.0 & 911.4 \\
\hline All & & & & 1.30 & 1.178 & 7055.0 & 6393.0 \\
\hline
\end{tabular}

estimate is 10708 and the total fishing mortality is 1.246 , which is not even the sum of nominal $F^{\prime \prime}$ s. For fleet 2 again, the partial fishing mortality based on the ratio of catches is estimated 10 be 0.575 . With this procedure, all estimates are in error and there is no obvious way of relating them with the exact figures. Ordinary VPA gets confused because it considers a single notion for fishing mortality, whereas equation [7], which was used to generate the catch data, uses corrected (in $Z$ ) and uncorrected $F^{\prime}$ s.

\section{DISCUSSION}

Although the usual assumption that all discards die after release may hold true for a majority of fisheries, notably when roundfish are concerned, there are instances in which an appreciable proportion of the discarded animals may survive. In order to deal with such cases, assessment methods must be expanded to account for survival of discards, or at least to test how significant its effects are in view of the generally large noise and variability in the discards data. This paper shows that this can easily be achieved with a simple modification of the standard model for age- or lengthstructured populations, as previously suggested by R. Jones. To some extent, this contradicts Restrepo's view (1992), that this model is not applicable when discards survive.

A major advantage of this approach is that it preserves the ability to estimate the parameters of the model by ordinary VPA, provided that removals rather than catches are used as input, and that care is taken of the nature of the estimated fishing mortalities (corrected $F^{\prime} \mathrm{s}$ ). The main objective of this paper was to examine how VPA results are altered when survival of discarded fish is taken into account. As expected, this results in lower fishing mortalities, since fewer fish are effectively killed. Perhaps more counter-intuitive is the finding that this also results in smaller estimates of the population number and biomass for the ages concerned. In Restrepo's words (Ibid.), the resource is partly "reusable" when some of the discards are allowed to survive, and can provide the same catches from a smaller initial size.

These effects were demonstrated on a single cohort, but would be similar when full arrays of data by age and year are analysed by VPA. In particular, the time series of recruitments and biomasses would take lower absolute values and, since the correction factors $K$ are bound to vary from year to year, primarily because discarding ratios vary, the perception of their relative changes through time may be altered as well. What is unclear, however, is how the VPA tuning procedures (Pope and Shepherd, 1985) need to be modified when the model's equations include discards survival. If removals are used as input then, for the sake of consistency, removals per unit effort should also be used as tuning data in procedures involving catches per unit effort. This may create a problem for all methods in which it is assumed that catchability remains constant through a period of years. For each tuning fleet $f$ and year $y$, these methods would use a relationship like:

$$
\frac{R_{i, f, y}}{E_{f, y}}=\frac{K_{i, f, y} C_{i, f, y}}{E_{f, y}}=K_{i, f, y} q_{i, f, y} \bar{N}_{i, y}
$$

where $E$ is the fishing effort and $q$ the catchability coefficient. The number of parameters is reduced by supposing that the latter is constant with respect to $y$, i.e. fishing efficiency and selectivity are stable. But if $K$ varies from year to year, for reasons stated above, then the apparent catchability (the product $K \times q$ ) measured by the ratio between removals per unit effort and population number in each year cannot be constant. Since the correction factors are known, it is possible to revert to catchability $q$ alone, but the computer program has to be amended accordingly.

Besides the possibility of using ordinary VPA, another clear advantage of the approach presented here is to make it straightforward to derive the partial fishing mortalities for multiple-fleet fisheries where discarding and survival rates are fleet specific, based on the ratio between partial and total removals. The implementation of this procedure in a multiple-species, multiple-fleet length-based VPA and simulation software typically involving 15-20 species and fleets, and up to 100 length classes has resulted in a huge improvement in runtime compared to previous pseudo-Newton multivariate algorithms. It became possible to use it on portable computers when these were much slower than they are now.

It should be kept in mind, however, that VPA estimates based on removals are what we called corrected fishing mortalities, and an important aspect of this paper is to clarify this point. Thus, if these 
estimates are input in forward predictions, typically using equations [3] or [6] and [4] or [7], care should be taken of not applying the correction again. It is probably safer to revert to nominal $F^{\prime \prime} s$ first, and to predict catches from which landings and removals can be derived easily. For simulations that involve changes in the landing ratios, and therefore imply different correction factors, a conversion to nominal $F^{\prime \prime} \mathrm{S}$ is necessary at some stage anyway. This conversion was shown to be simple, using catch-to-removal ratios (eq. [13]).

In view of the diversity of possible options for simulations, this paper does not attempt to examine the effects of the survival of discards on predictions of catches and biomasses. Since lower estimates of fishing mortalities go along with reduced stock numbers, it is likely that some compensation occurs and that there are small differences in the catches or landings predicted in the short-term under moderate departures from status quo fishing mortality.
Predicted biomasses would be smaller in absolute value but relative changes should be similar if constant discarding and survival rates are assumed. Allowing the discards to survive was shown to be equivalent to applying lower fishing mortalities, and the effects on long-term simulations should be similar to those of reducing fishing effort, or of improving the exploitation patterns if the discards are essentially composed of young fish. In the same vein, if many young discarded fish survive, there are less gains to be expected from an increase in mesh-size, which may not be as urgently needed. In terms of management, measures to improve the survival of released fish (if feasible and effective) might be traded against the always unpopular mesh size increases. However, the results presented in this paper indicate that the conservation effects of such measures are achieved by removing the fish at a larger size and making better use of recruitment for a given effort, rather than by increasing the exploitable biomass.

\section{Acknowledgements}

This work is just a slight progress along a way paved initially by Rodney Jones and Alain Laurec. Marc Labelle provided helpful comments on a first draft. Further improvements were suggested by two anonymous referees.

\section{REFERENCES}

Alverson D. L., M. H. Freeberg, J. G. Pope, S. A. Murawski 1994. A global assessment of fisheries bycatch and discards. FAO Fish. Tech. Pap. 339, 233 p.

Anon. 1979. Report of the Nephrops Working Group. Cons. int. Explor. Mer C.M.1979/K, 2, 71 p.

Anon. 1980. Report of the Nephrops Working Group. Cons. int. Explor. Mer C.M.1980/K, 2, 46 p.

Anon. 1986. Report of the Working Group on Methods of Fish Stock Assessments (November 1985). Cons. int. Explor. Mer C.M.1986/Assess., 10, 92 p.

Anon. 1990. Report of the Working Group on Fisheries Units in Sub-Areas VII and VIII, Cons. int. Explor. Mer C.M.1990/Assess., 23, 129 p.

Anon. 1992. Report of the Study Group on Ecosystem Effects of Fishing Activities. Cons. int. Explor. Mer C.M.1992/G, 11, 144 p.

Berghahn R., M. Waltemath, A. D. Rijnsdorp 1992. Mortality of fish from the bycatch of shrimp vessels in the North Sea. J. Appl. Ichthyol. 8, 293-306.

CFC 1992. Report from the Commission to the Council on the discarding of fish in Community fisheries: causes, impact, solutions. Commission of the European Communities, Sec. (92) 423 final.

Gillis D. M., R. M. Peterman, E. K. Pikitch 1995. Implications of trip regulations for high-grading: a model of the bchavior of fishermen. Can. J. Fish. Aquat. Sci. $52,402-415$.
Gueguen J., A. Charuau 1975. Essai de détermination du taux de survie des langoustines hors-taille rejetées lors des opérations de pêche commerciale. Cons. int. Explor. Mer C.M.1975/K, 12.

Hill B. J., T. J. Wassenberg 1990. Fate of discards from prawn trawlers in Torres Strait. Aust. J. Mar. Freshw. Res. 41, 53-64.

Megrey B. A. 1989. Revicw and comparison of agestructured stock assessment models from theoretical and applied points of view. Am. Fish. Soc. Symp. 6, 8-48.

Mesnil B., J. G. Shepherd 1990. A hybrid age- and lengthstructured model for assessing regulatory measures in multiple-species, multiple-fleet fisheries. J. Cons. int. Explor. Mer 47, 115-132.

Murawski S. A. 1993. Factors influencing by-catch and discard rates: analyses from multispecies/multifishery sea sampling. NAFO SCR Doc. 93/115, 17 p.

Neilson J. D., K. G. Waiwond, S. J. Smith 1989. Survival of Atlantic halibut (Hippoglossus hippoglossus) caught by longline and otter trawl gear. Can. J. Fish. Aquat. Sci. 46, 497-524.

Pope J. G., J. G. Shepherd 1985. A comparison of the performance of various methods for tuning VPAs using effort data. J. Cons. int. Explor. Mer 42, 129-151.

Restrepo V. R. 1992. A mortality model for a population in which harvested individuals do not necessarily die: the stone crab. Fish. Bull. U.S. 90, 412-416.

Ricker W. E. 1976. Review of the rate of growth and mortality of Pacific salmon in salt water, and non-catch 
mortality caused by fishing. J. Fish. Res. Board Can. 33, 1483-1524.

Stevens B. G. 1990. Survival of king and Tanner crabs captured by commercial sole trawls. Fish. Bull. U.S. 6o, 731-744.

van Beek F. A., P. I. van Leeuwen, A. D. Rijnsdorp 1990. On the survival of plaice and sole discards in the ottertrawl and beam-trawl fisheries in the North Sea. Neth. J. Sea lies. 20, 151-160.
Wassenberg T. J., B. J. Hill 1989. The effects of trawling and subsequent handling on the survival rates of the bycatch of prawn trawlers in Moreton Bay, Australia. Fish. Res. 7, 99-110.

Williams G. H., C. C. Schmitt, S. H. Hoag, J. D. Berger 1989. Incidental catch and mortality of Pacific halibut, 1962-1986. International Pacific Halibut Commission Tech. Rep. 23. 